\title{
Insulin-like Growth Factor-1, IGF-binding Protein-3, C-peptide and Colorectal Cancer: a Case-control Study
}

\author{
Pankaj Joshi ${ }^{1,3}$, Rakhi Kumari Joshi ${ }^{1}$, Woo Jin Kim² ${ }^{2}$,Sang-Ah Lee ${ }^{1,3 *}$
}

\begin{abstract}
Context: Insulin-like growth factor peptides play important roles in regulating cell growth, cell differentiation, and apoptosis, and have been demonstrated to promote the development of colorectal cancer (CRC). Objective: To examine the association of insulin-related biomarkers including insulin-like growth factor-1 (IGF-1), insulin-like growth factor binding protein-3 (IGFBP-3) and C-peptide with CRC risk and assess their relevance in predictive models. Materials and Methods: The odds ratios of colorectal cancer for serum levels of IGF-1, IGFBP-3 and $\mathrm{C}$-peptide were estimated using unconditional logistic regression models in 100 colorectal cancer cases and 100 control subjects. Areas under the receiving curve (AUC) and integrated discrimination improvement (IDI) statistics were used to assess the discriminatory potential of the models. Results: Serum levels of IGF-1 and IGFBP-3 were negatively associated with colorectal cancer risk $(\mathrm{OR}=0.07,95 \% \mathrm{CI}$ : $0.03-0.16, \mathrm{P}$ for trend $<.01$, $\mathrm{OR}=0.06,95 \% \mathrm{CI}: \mathbf{0 . 0 3 - 0 . 1 5}, \mathrm{P}$ for trend $<.01$ respectively) and serum $\mathrm{C}$-peptide was positively associated with risk of colorectal cancer $(\mathrm{OR}=4.38,95 \% \mathrm{CI}: \mathbf{2 . 1 3 - 9 . 0 6}$, P for trend <.01). Compared to the risk model, prediction for the risk of colorectal cancer had substantially improved when all selected biomarkers IGF-1, IGFBP-3 and inverse value of $\mathrm{C}$-peptide were simultaneously included inthe reference model [Pfor AUC improvement was 0.02 and the combined IDI reached $0.166 \%$ (95 \% CI; 0.114-0.219)]. Conclusions: The results provide evidence for an association of insulin-related biomarkers with colorectal cancer risk and point to consideration as candidate predictor markers.
\end{abstract}

Keywords: Colorectal cancer - insulin-related biomarkers (IGF-1, IGFBP-3, C-peptide) - case-control study

Asian Pac J Cancer Prev, 16 (9), 3735-3740

\section{Introduction}

Colorectal cancer (CRC) is a significant public health concern with over 1 million new cases occurring every year worldwide (Ferlay et al., 2010) with increased prevalence in developed countries and increased incidence and mortality in developing countries as well (Jemal et al., 2011).Although the pathogenesis of CRC still remains unclear, hyperinsulinemia or insulin resistance has been suggested as one of the major biological pathways to link obesity and CRC and has been hypothesized mediated by increasing exposure to the pro-mitotic and anti-apoptotic effects of insulin and insulin-like growth factor peptides (Sandhu et al., 2002).

High-caloric diets, sedentary lifestyle, and obesity (Joshi and Lee, 2014) are prominent risk factors for CRC and these associated risk factors have been proposed to result from the proliferative and anti-apoptotic effects of the increased circulating insulin levels that are observed among overweight and obese individuals (Giovannucci, 2001). Insulin is a key to the regulation of energy metabolism and may directly influence CRC risk via mitogenic/antiapoptotic effects through the insulin receptor (Tran et al., 2006). Insulin-like growth factor
(IGF) signaling pathway is involved in cell proliferation and differentiation, having a central role in growth regulation at both cellular and organism levels(Pollak, 2008). Indirectly, elevated insulin also suppresses the production of insulin-like growth factor binding protein, which inhibits insulin-like growth factor (IGF1)-1-stimulated cell growth and differentiation leading to elevated IGF-1 bioactivity (Sandhu et al., 2002; Kaaks, 2004). Higher IGF-1 level has been reported to be associated with neoplastic progression and reduced apoptosis, which may lead to an increased risk of CRC (Khandwala et al., 2000; Sandhu et al., 2002), and also increases insulin-like growth factor binding protein-3 (IGFBP-3), which has IGF-1-dependent and independent antiproliferative effects (Firth and Baxter, 2002; Sandhu et al., 2002). Moreover, it has been hypothesized that the direct markers of hyperinsulinemia including IGF-1 and C-peptide (a marker of insulin secretion) levels may be associated with the increased risk of CRC (Kaaks et al., 2000; Giovannucci, 2001; Ma et al., 2004; Wei et al., 2005; Otani et al., 2007).

Several prospective epidemiological studies have reported the specific association of circulating levels of IGF-1, IGFBP-3 and C-peptide with CRC risk; however, 
the results were not always consistent (Kaaks et al., 2000; Probst-Hensch et al., 2001; Nomura et al., 2003; Palmqvist et al., 2003; Ma et al., 2004; Wei et al., 2005; Otani et al., 2007; Gunter et al., 2008). Some studies have shown that high concentration of IGF-1 increased CRC risk (Ma et al., 1999; Giovannucci et al., 2000), but others did not (Probst-Hensch et al., 2001; Nomura et al., 2003; Rinaldi et al., 2010). In an EPIC study, there was no significant association between IGF-1 and CRC risk, which so far was the largest study investigating IGF-1 levels in relation to CRC risk(Rinaldi et al., 2010). In addition, the association between IGFBP-3 and CRC risk was more controversial (Ma et al., 1999; Giovannucci et al., 2000; Otani et al., 2007; Rinaldi et al., 2010). A study by Kaaks et al. (2000) observed a significant increased risk of CRC, however other studies (Ma et al., 1999; Nomura et al., 2003) have shown an inverse association between IGFBP-3 and $\mathrm{CRC}$ risk. It has been hypothesized that direct markers of hyperinsulinemia including insulin and C-peptide levels may be associated with the risk of CRC (Kaaks et al., 2000; Giovannucci, 2001). Higher circulating concentrations of C-peptide were shown to be associated with a moderately increased risk of CRC in number of studies (Kaaks et al., 2000; Ma et al., 2004; Jenab et al., 2007), whereas two prospective studies (Kabat et al., 2012; Ollberding et al., 2012) did not observe any association.

Thus, the objectives of this study were to examine the association of insulin-related biomarkers including IGF-1, IGFBP-3, and C-peptide with colorectal cancer risk, and to statistically show the cumulative effect of selected insulin related biomarkers on increased risk of CRC.

\section{Materials and Methods}

\section{Study subjects}

The bio specimens for this study were collected from the Keimyung Human Bio-Resource Bank (KHBB), a member of the National Bio-bank of Korea, supported by the Ministry of Health and Welfare, Korea and Kangwon National University Bio Bank (KNUB). All samples were therefore derived from the National Bio-bank of Korea with informed consent under institutional review board-approved protocols. After approval of the study protocols the study was undertaken at Keimyung and Kangwon National University Hospital during 20092011. The patients from Keimyung University Hospital who had been newly and pathologically diagnosed with colorectal cancer by biopsy using colonoscopy were identified as colorectal cancer patients. Similarly, age- and sex-matched controls from Kangwon National University Hospital were identified among the individuals that were diagnosed negative for colorectal cancer by carcinoembryonic antigen (CEA) serological blood test. The cases and controls were then subsequently matched for each was (100:100) as selected for the study. The cut of age range for the analysis were $(\leq 60,61-70$, and $\geq 71)$ in selected cases and controls. The study was approved by the National Bio-bank of Korea, and all participants provided informed consent under institutional review board-approved protocols (IRB No. 2010-10-008).

\section{Laboratory Methods}

Blood samples were collected from the patients and age, sex matched individuals. Separated serums from the blood samples were stored at $-20^{\circ} \mathrm{C}$ for the further analysis. Serum levels of IGF-1 and C-peptide were determined by Enzyme Immunoassay (EIA) method (Enzo Life Science, USA) and IGFBP-3 was measured using Enzyme-linked immunosorbent assay (ELISA) (AdipoMark, Korea). The sensitivity of the assay was $34.2 \mathrm{pg} / \mathrm{ml}$ for IGF-1, <10 pg/ $\mathrm{ml}$ for IGFBP-3, and $772 \mathrm{pg} / \mathrm{ml}$ for C-peptide. The intraassay precision of variation was $8.9-3.6 \%$ for IGF-1, and $<10 \%$ for IGFBP-3 and C-peptide. The measurements of each adipokines were performed according to manufacturer's protocol.

\section{Statistical analysis}

Comparison of continuous and categorical variables between cases and controls were made using t-test and $\mathrm{x}^{2}$ test, respectively. The relationship between biomarkers

Table 1. Serum Levels of Insulin-related Biomarkers of Colorectal Cancer Cases and Controls

\begin{tabular}{|c|c|c|c|c|c|}
\hline & & Total (mean \pm S.D) & Case $($ mean \pm S.D) & Control (mean \pm S.D) & $\mathrm{P}^{\mathrm{a}}$ \\
\hline \multirow[t]{4}{*}{ Age } & Overall & $66.5 \pm 10.0$ & $66.1 \pm 10.0$ & $66.9 \pm 10.0$ & 0.67 \\
\hline & $\leq 60$ & $39(19.5)$ & $20(20.0)$ & $19(19.0)$ & \\
\hline & $60-70$ & $87(43.5)$ & $46(46.0)$ & $41(41.0)$ & \\
\hline & $70 \leq$ & $74(37.0)$ & $34(34.0)$ & $40(40.0)$ & \\
\hline \multirow[t]{2}{*}{ Sex } & Male & 120 & 60 & 60 & \\
\hline & Female & 80 & 40 & 40 & \\
\hline \multirow[t]{3}{*}{ IGF-1(ng/mL) } & Overall & $123 \pm 47$ & $95 \pm 42$ & $152 \pm 57$ & $<0.01$ \\
\hline & Male & $114 \pm 55$ & $87 \pm 37$ & $141 \pm 58$ & $<0.01$ \\
\hline & Female & $137 \pm 58$ & $106 \pm 46$ & $169 \pm 51$ & $<0.01$ \\
\hline \multirow[t]{3}{*}{ IGFBP-3(ng/mL) } & Overall & $2895 \pm 802$ & $2575 \pm 777$ & $3215 \pm 696$ & $<0.01$ \\
\hline & Male & $2705 \pm 633$ & $2386.1 \pm 535$ & $3023.8 \pm 563$ & $<0.01$ \\
\hline & Female & $3181 \pm 938$ & $2859.7 \pm 980$ & $35041 \pm 779$ & $<0.01$ \\
\hline \multirow[t]{3}{*}{ C-peptide(ng/mL) } & Overall & $3.2 \pm 7.0$ & $2.6 \pm 3.6$ & $3.8 \pm 9.1$ & 0.24 \\
\hline & Male & $3.6 \pm 8.2$ & $2.9 \pm 4.6$ & $4.3 \pm 10.7$ & 0.35 \\
\hline & Female & $2.6 \pm 4.4$ & $2.2 \pm 1.3$ & $3.0 \pm 6.1$ & 0.44 \\
\hline \multirow[t]{3}{*}{ IGF-1/IGFBP-3 } & Overall & $0.04 \pm 0.02$ & $0.04 \pm 0.01$ & $0.05 \pm 0.02$ & $<0.01$ \\
\hline & Male & $0.04 \pm 0.02$ & $0.04 \pm 0.01$ & $0.05 \pm 0.02$ & $<0.01$ \\
\hline & Female & $0.04 \pm 0.02$ & $0.04 \pm 0.01$ & $0.05 \pm 0.02$ & $<0.01$ \\
\hline
\end{tabular}

$\mathrm{P}^{\mathrm{a}}$ value for the comparison of cases and controls by $\mathrm{t}$ test or $\mathrm{x}^{2}$ test, as appropriate. Values are expressed as mean \pm S.D or $\mathrm{N}$ as appropriate 
(IGF-1, IGFBP-3, and C-peptide) and colorectal cancer were assayed in the study population by comparing mean values between case and control subjects using t-tests. The distribution of IGF-1, IGFBP-3 and C-peptide measures among subjects was used to generate tertiles values. The lowest tertiles of each measure was considered as the reference. Unconditional logistic regression models were used to examine the association between CRC and IGF-1, IGFBP-1, C-peptide, and expressed as odds ratios (OR) with $95 \%$ confidence intervals (CI). We also examined the molar ratio of IGF-1 to IGFBP-3, a surrogate estimate of free IGF-1 ( $1 \mathrm{ng} / \mathrm{ml} \mathrm{IGF-1=0.130} \mathrm{nmol/L;} 1 \mathrm{ng} / \mathrm{mL}$ IGFBP-3=0.036 nmol/L).

The improvement in colorectal cancer prediction performance attributed to the biomarkers was measured by the analysis of area under the receiver curves (AUC) and the difference ability was evaluated measuring Integrated Discrimination Improvement (IDI), which is independent of class limit. For the purpose of analysis, we used the continuous biomarkers IGF-1, IGFBP-3, and inverse value of $\mathrm{C}$-peptide (1/C-peptide). The feature with the highest AUC was first to be included in the model and later measures the percentage of increased discrimination upon addition of another variable to the prediction model. The added prediction performance

Table 2. Odds Ratios and 95\% Confidence Intervals for Tertiles of Each Biomarker Level and Colorectal Cancer Risk

\begin{tabular}{|c|c|c|c|c|}
\hline & $\begin{array}{c}\text { Case } \\
(\mathrm{N}=100)\end{array}$ & $\begin{array}{r}\text { Control } \\
(\mathrm{N}=100)\end{array}$ & $\begin{array}{l}\text { Mean } \\
\text { levels }\end{array}$ & OR \\
\hline \multicolumn{5}{|c|}{ IGF-1(ng/mL) } \\
\hline $1^{\text {st }}$ tertile & 52 & 14 & $66.0 \pm 10.5$ & ref. \\
\hline $2^{\text {nd }}$ tertile & 34 & 33 & $109 \pm 18.9$ & $0.28(0.13-0.59)$ \\
\hline $3^{\text {rd }}$ tertile & 14 & 53 & $195.2 \pm 28.7$ & $0.07(0.03-0.16)$ \\
\hline P-trend & & & & $<.01$ \\
\hline \multicolumn{5}{|c|}{ IGFBP-3(ng/mL) } \\
\hline $1^{\text {st }}$ tertile & 57 & 10 & $2114.3 \pm 260$ & ref. \\
\hline $2^{\text {nd }}$ tertile & 26 & 412 & $2798.8 \pm 207.7$ & $0.11(0.05-0.26)$ \\
\hline $3^{\text {rd }}$ tertile & 17 & 493 & $3787.4 \pm 643.8$ & $0.06(0.03-0.15)$ \\
\hline P-trend & & & & $<.01$ \\
\hline \multicolumn{5}{|c|}{ C-peptide (ng/mL) } \\
\hline $1^{\text {st }}$ tertile & 22 & 45 & $1.20 \pm 0.04$ & ref. \\
\hline $2^{\text {nd }}$ tertile & 33 & 34 & $1.68 \pm 0.25$ & $1.99(0.99-4.00)$ \\
\hline $3^{\text {rd }}$ tertile & 45 & 21 & $6.80 \pm 11.3$ & $4.38(2.12-9.06)$ \\
\hline P-trend & & & & $<.01$ \\
\hline \multicolumn{5}{|c|}{ IGF-1/IGFBP-3 } \\
\hline $1^{\text {st }}$ tertile & 39 & 28 & $0.03 \pm 0.01$ & ref. \\
\hline $2^{\text {nd }}$ tertile & 46 & 21 & $0.04 \pm 0.01$ & $1.57(0.77-3.19)$ \\
\hline $3^{\text {rd }}$ tertile & 15 & 51 & $0.06 \pm 0.01$ & $0.21(0.10-0.45)$ \\
\hline P-trend & & & & $<.01$ \\
\hline
\end{tabular}

$\mathrm{N}$ : Number of case or controls. ORs estimated using age, sex matched and following mentioned serum measurements: IGF-1, IGFBP-3, C-peptide or IGF-1/IGFBP-3 was determined separately for each identified biomarker as statistically associated with the cancer risk (in logistic regression analysis steps), and then for a combination of these biomarkers simultaneously. The significance in IDI was tested using a simple asymptotic Z-test and $\mathrm{P}<0.05$ was considered significant (DeLong et al., 1988). All the statistical analyses were performed using SAS statistical software (version 9.2, SAS Institute).

\section{Results}

The baseline characteristics of a hundred matched case-controls were included in the analysis as shown in Table 1 . Of the total participants, $60 \%$ were males and $40 \%$ were females. The average age of case was 66.1 years and of control was 66.9 years. The mean serum levels of both IGF-1 (123 \pm 47$)$ and IGFBP-3 (2895 \pm 802$)$ were significantly lower in cases than controls ( $\mathrm{P}$ $<0.01)$. Similarly, IGF-1/IGFBP-3 ratio was also found significantly lower in cases than controls $(\mathrm{P}<0.01)$ and its value was same for male and female $(\mathrm{P}<0.01)$. For cases and controls the serum level of IGF-1 and IGFBP-3 were found lower in male than female. Also, the mean serum levels of IGF-1 and IGFBP-3 of both male and female were significantly lower in cases than controls $(\mathrm{P}<0.01)$. The mean levels of circulating $\mathrm{C}$-peptide in cases were not different from controls (Table 1).

Table 2 summarizes the ORs of colorectal cancer according to tertile of IGF-1, IGFBP-3, and C-peptide. Serum levels of IGF-1 and IGFBP-3 were inversely associated with $\mathrm{CRC}$ risk and we found statistically significant trends indicating decreased risk for subjects in the high compared to the low tertile $(\mathrm{OR}=0.07,95 \% \mathrm{CI}$ : $0.03-0.16$, P for trend $<0.01, \mathrm{OR}=0.06,95 \% \mathrm{CI}: 0.03-0.15$, $\mathrm{P}$ for trend $<0.01$ respectively). In addition, tertiles of IGF-1/IGFBP-3 molar ratio were negatively associated with increased risk of $\mathrm{CRC}(\mathrm{OR}=0.21,95 \% \mathrm{CI}$ : $0.10-0.45$, $\mathrm{P}$ for trend $<0.01$, low $v s$ high tertile). On the other hand, compared to those with the lowest tertile (t1) of C-peptide levels, levels of those analytes in the third tertile $(\mathrm{t} 3)$ were associated with a more than 4-fold increased risk of $\mathrm{CRC}$ and thus serum levels of C-peptide were positively associated with higher risk of $\mathrm{CRC}(\mathrm{OR}=4.38,95 \% \mathrm{CI}$ : 2.13-9.06, P for trend <0.01) (Table 2).

The predictive quality in terms of AUC and IDI statistics were used to evaluate the risk model among insulinrelated biomarkers to discriminate the CRC cases from controls (Table 3 ). We built prediction model (reference model) IGFBP-3 with the AUC (0.78). The AUC values of IGFBP-3, IGFBP-3+1/C-peptide and IGFBP-3+1/Cpeptide+IGF-1 were $0.78,0.79$ and 0.85 respectively. Indicators of the predictive potential of CRC risk

Table 3. Predictive Potential of Insulin-related Biomarkers Regarding the Risk of Colorectal Cancer: Integrated Discrimination Improvements and Improvement of Area Under Curve

\begin{tabular}{lccccc}
\hline Model & AUC & AUC difference & P-value for AUC difference & IDI & $95 \%$ CI \\
\hline IGFBP-3 & 0.78 & & & & \\
IGFBP-3+1/C-peptide & 0.79 & 0.01 & 0.06 & 0.04 & $(0.01-0.07)$ \\
IGFBP-3+1/C-peptide+IGF-1 & 0.85 & 0.07 & 0.02 & 0.17 & $(0.11-0.22)$ \\
\hline
\end{tabular}

In reference to IGFBP-3 AUC (area under curve) and IDI (Integrated discrimination improvements) were estimated for age and sex matched 100 cases and 100 controls; CI: Confidence interval 
models in Table 3 showed an improvement when two biomarkers IGFBP-3 and inverse value of C-peptide were included in the reference model (AUC was 0.79 , and $\mathrm{P}$ for $\mathrm{AUC}=0.06$ ). The IDI statistic indicated a $0.04 \%$ (0.01-0.07) improvement. Prediction was substantially improved when IGFBP-3, IGF-1, and inverse value of C-peptide (1/C-peptide) were simultaneously included in the reference model: $\mathrm{P}$ for AUC improvement was 0.02 and the IDI reached $0.17 \%(0.11-0.22)$.

\section{Discussion}

In this case-control study, we evaluated the statistical relationship of insulin related biomarkers namely IGF-1, IGFBP-3 and C-peptide with the risk of CRC. We found significant lower serum level of IGF-1 and IGFBP-3 in cases than controls. Also, we observed an inverse association of serum levels of IGF-1 and IGFBP-3 with colorectal cancer risk and clear positive association of serum C-peptide with risk of colorectal cancer. Significantly an improved discriminatory abilities and predictive performance was observed by AUC and IDI statistics compared to the risk model.

From the evidence of epidemiologic studies, role of IGF-1 has been established as proliferative, antiapoptotic effects on colorectal lesions (Giovannucci, 2001; Durai et al., 2005; Davies et al., 2006), and bioavailability of free IGF-1 has been suggested as a potential mediator of the direct association between obesity and CRC risk (Sandhu et al., 2002). Several studies have reported that increased IGF-1 is consistently found to be associated with increased risk of CRC (Ma et al., 1999; Kaaks et al., 2000; Palmqvist et al., 2002; Wei et al., 2005), but not in others (Probst-Hensch et al., 2001; Otani et al., 2007). Our current study result has shown a significant inverse association of IGF-1 with CRC risk. In our study, the level of IGF-1 in CRC patients is relatively lower than those reported in some previous studies (Ma et al., 1999; Kaaks et al., 2000; Renehan et al., 2004; Rinaldi et al., 2010). In these studies, the mean levels of IGF-1 approximately presented in CRC cases and controls were $199.9 \mathrm{ng} / \mathrm{ml}$ and $207.0 \mathrm{ng} / \mathrm{ml}$, respectively, whereas in our study the means were $95 \mathrm{ng} / \mathrm{ml}$ and $152 \mathrm{ng} / \mathrm{ml}$ for the $\mathrm{CRC}$ cases and controls respectively. Our highest tertile for IGF-1 levels roughly corresponds with the lowest quintile of those studies which showed the modest positive association for the risk of CRC with increased IGF-1. Another consideration of this current study is that almost $40 \%$ of patients in our study population were in advanced stage of colorectal cancer. In advanced cancer, circulating levels of IGF-1 falls generally regardless of the evidences that high IGF-1 levels are related to increased CRC risk and this low IGF-1 levels in advanced cancer have been recognized to be associated with malnourishment and/or cachexia (Pollak, 2000). In this way it might be possible to observe an inverse association of IGF-1 with CRC risk. Thus, in previous studies the increased risk for colorectal cancer has been reported at the increased level of IGF-1 concentrations and our relatively lower levels does not explain the differences between our study and others. Therefore, more advanced prospective studies are needed for further investigations.

Although any actions of IGFBP-3 can be expected to reduce the risk of CRC, epidemiological findings are not always consistent (Renehan et al., 2004). Some studies reported that IGFBP-3 is not inversely associated with CRC risk (Kaaks et al., 2000; Probst-Hensch et al., 2001; Palmqvist et al., 2002); however, our colorectal cancer result for IGFBP-3 are consistent with US Health Professional Cohorts that reported an inverse association between IGFBP-3 and the risk of CRC (Ma et al., 1999; Wei et al., 2005). The serum levels of IGFBP-3 in cases than in controls also vary from study to study and our data supports the lower concentration in cases than controls. Lower plasma IGFBP-3 concentration is associated with an increased risk of CRC among both men and women (Giovannucci et al., 2000) and this association is statistically significant only after adjustment for each other (Ma et al., 1999; Giovannucci et al., 2000). Other important determinants of IGBP-3 (Ferry et al., 1999), or use of different assay methods adopted (Palmqvist et al., 2002), or study population from different ethnics may have played important role in inconsistent results for the association of IGFBP-3 with CRC risk.

The baseline plasma C-peptide levels in case were not found significant in comparison to controls but however CRC risk was found to be positively associated with serum C-peptide. The finding of this study that colorectal cancer risk is positively associated with levels of serum C-peptide is consistent with findings from previous epidemiological studies (Schoen et al., 1999; Kaaks et al., 2000; Ma et al., 2004; Wei et al., 2005; Otani et al., 2007). Kaaks et al (Kaaks et al., 2000) study found nearly threefold increase in risk of CRC in individuals with high serum C-peptide levels which supported our finding of more than fourfold increase in CRC risk when lowest tertile were compared to third tertile.

In advanced analysis, for the association between these selected insulin-related biomarkers and CRC risk, we evaluated the contribution of these biomarkers in predicting colorectal cancer risk for Korean population. As shown in Table 3, the IDI statistic suggests that when tertiles of IGF-1, IGFBP-3 and 1/C-peptide serum levels are added to the model, the ability of the model to predict colorectal cancer risk is improved by $0.17 \%$, compared to the model including only individual biomarker. Thus this result suggests that IGFBP-3, IGF-1, and possibly $\mathrm{C}$-peptide might be considered as candidate of predictor markers for CRC risk; however, additional prospective and validation studies are needed to confirm and better quantify the predictive performance.

Our study has some limitations. We used a single measurement of blood samples of IGF-1, IGFBP-3 and C-peptide at baseline, which may be susceptible to short-term variation and could bias results towards the null, and we have also not included confounder factors such as BMI, smoking status, alcohol consumption, etc. With insufficient data on height, the effect of BMI and its interaction with insulin-related biomarkers and the risk of CRC was not included and the present analysis is inconclusive as to whether IGF-1, IGFBP-3 and $\mathrm{C}$-peptide explains the association of obesity with CRC. 
Besides these limitations, our study has strengths too. This study has included the simultaneous measurement of three biomarkers and assessment of the discriminatory capabilities of these biomarkers for estimating colorectal cancer risk by the IDI statistics.

In summary, inverse association of IGF-1 and IGFBP-3 with CRC risk and a positive association of C-peptide with the risk of CRC were observed. In conclusion, our result suggest that the IGF-1, IGFBP-3 and C-peptide levels may predict the risk of developing $\mathrm{CRC}$; however, large scale prospective studies will confirm the pertinence of these biomarkers in colorectal cancer risk prediction.

\section{Acknowledgements}

We would like to thank all the staff members involved in each study area for their valuable efforts in conducting the baseline surveys. The bio-specimens for this study were provided by the Keimyung Human Bio-Resource Bank (KHBB), a member of the National Biobank of Korea, which is supported by the Ministry of Health and Welfare. All samples derived from the National Biobank of Korea were obtained with informed consent under institutional review board-approved protocols. This study was supported by a grant from the Basic Science Research Program through the National Research Foundation of Korea (NRF) funded by the Ministry of Education, Science and Technology (2010-0017355) and also supported by a grant from National R and D Program for Cancer Control, Ministry of Health and Welfare, Republic of Korea (1020420).

\section{References}

Davies M, Gupta S, Goldspink G, et al (2006). The insulin-like growth factor system and colorectal cancer: clinical and experimental evidence. Int J Colorectal Dis, 21, 201-8.

DeLong ER, DeLong DM, Clarke-Pearson DL (1988). Comparing the areas under two or more correlated receiver operating characteristic curves: a nonparametric approach. Biometrics, 44, 837-45.

Durai R, Yang W, Gupta S, et al (2005). The role of the insulinlike growth factor system in colorectal cancer: review of current knowledge. Int J Colorectal Dis, 20, 203-20.

Ferlay J, Shin HR, Bray F, et al (2010). Estimates of worldwide burden of cancer in 2008: GLOBOCAN 2008. Int J Cancer, 127, 2893-917.

Ferry RJ, Jr., Cerri RW, Cohen P (1999). Insulin-like growth factor binding proteins: new proteins, new functions. Horm Res, 51, 53-67.

Firth SM, Baxter RC (2002). Cellular actions of the insulin-like growth factor binding proteins. Endocr Rev, 23, 824-54.

Giovannucci E (2001). Insulin, insulin-like growth factors and colon cancer: a review of the evidence. J Nutr, 131,3109-20.

Giovannucci E, Pollak MN, Platz EA, et al (2000). A prospective study of plasma insulin-like growth factor-1 and binding protein-3 and risk of colorectal neoplasia in women. Cancer Epidemiol Biomarkers Prev, 9, 345-9.

Gunter MJ, Hoover DR, Yu H, et al (2008). Insulin, insulin-like growth factor-I, endogenous estradiol, and risk of colorectal cancer in postmenopausal women. Cancer Res, 68, 329-37.

Jemal A, Bray F, Center MM, et al (2011). Global cancer statistics. CA Cancer J Clin, 61, 69-90.

Jenab M, Riboli E, Cleveland RJ, et al (2007). Serum C-peptide,
IGFBP-1 and IGFBP-2 and risk of colon and rectal cancers in the European Prospective Investigation into Cancer and Nutrition. Int J Cancer, 121, 368-76.

Joshi RK, Lee SA (2014). Obesity related adipokines and colorectal cancer: a review and meta-analysis. Asian Pac J Cancer Prev, 15, 397-405.

Kaaks R (2004). Nutrition, insulin, IGF-1 metabolism and cancer risk: a summary of epidemiological evidence. Novartis Found Symp, 262, 247-60.

Kaaks R, Toniolo P, Akhmedkhanov A, et al (2000). Serum C-peptide, insulin-like growth factor (IGF)-I, IGF-binding proteins, and colorectal cancer risk in women. J Natl Cancer Inst, 92, 1592-600.

Kabat GC, Kim MY, Strickler HD, et al (2012). A longitudinal study of serum insulin and glucose levels in relation to colorectal cancer risk among postmenopausal women. $\mathrm{Br} \mathrm{J}$ Cancer, 106, 227-32.

Khandwala HM, McCutcheon IE, Flyvbjerg A, et al (2000). The effects of insulin-like growth factors on tumorigenesis and neoplastic growth. Endocr Rev, 21, 215-44.

Ma J, Giovannucci E, Pollak M, et al (2004). A prospective study of plasma C-peptide and colorectal cancer risk in men.J Natl Cancer Inst, 96, 546-53.

Ma J, Pollak MN, Giovannucci E, et al (1999). Prospective study of colorectal cancer risk in men and plasma levels of insulin-like growth factor (IGF)-I and IGF-binding protein-3. J Natl Cancer Inst, 91, 620-5.

Nomura AM, Stemmermann GN, Lee J, et al (2003). Serum insulin-like growth factor I and subsequent risk of colorectal cancer among Japanese-American men. Am J Epidemiol, 158, 424-31.

Ollberding NJ, Cheng I, Wilkens LR, et al (2012). Genetic variants, prediagnostic circulating levels of insulin-like growth factors, insulin, and glucose and the risk of colorectal cancer: the Multiethnic Cohort study. Cancer Epidemiol Biomarkers Prev, 21, 810-20.

Otani T, Iwasaki M, Sasazuki S, et al (2007). Plasma C-peptide, insulin-like growth factor-I, insulin-like growth factor binding proteins and risk of colorectal cancer in a nested case-control study: the Japan public health center-based prospective study. Int J Cancer, 120, 2007-12.

Palmqvist R, Hallmans G, Rinaldi S, et al (2002). Plasma insulinlike growth factor 1 , insulin-like growth factor binding protein 3, and risk of colorectal cancer: a prospective study in northern Sweden. Gut, 50, 642-6.

Palmqvist R, Stattin P, Rinaldi S, et al (2003). Plasma insulin, IGF-binding proteins-1 and -2 and risk of colorectal cancer: a prospective study in northern Sweden. Int J Cancer, 107, 89-93.

Pollak M (2000). Insulin-like growth factor physiology and cancer risk. Eur J Cancer, 36, 1224-8.

Pollak M (2008). Insulin and insulin-like growth factor signalling in neoplasia. Nat Rev Cancer, 8, 915-28.

Probst-Hensch NM, Yuan JM, Stanczyk FZ, et al (2001). IGF-1, IGF-2 and IGFBP-3 in prediagnostic serum: association with colorectal cancer in a cohort of Chinese men in Shanghai. Br J Cancer, 85, 1695-9.

Renehan AG, Zwahlen M, Minder C, et al (2004). Insulin-like growth factor (IGF)-I, IGF binding protein-3, and cancer risk: systematic review and meta-regression analysis. Lancet, 363, 1346-53.

Rinaldi S, Cleveland R, Norat T, et al (2010). Serum levels of IGF-I, IGFBP-3 and colorectal cancer risk: results from the EPIC cohort, plus a meta-analysis of prospective studies. Int J Cancer, 126, 1702-15.

Sandhu MS, Dunger DB, Giovannucci EL (2002). Insulin, insulin-like growth factor-I (IGF-I), IGF binding proteins, 
Joshi Pankaj et al

their biologic interactions, and colorectal cancer. $J$ Natl Cancer Inst, 94, 972-80.

Schoen RE, Tangen CM, Kuller LH, et al (1999). Increased blood glucose and insulin, body size, and incident colorectal cancer. J Natl Cancer Inst, 91, 1147-54.

Tran TT, Naigamwalla D, Oprescu AI, et al (2006). Hyperinsulinemia, but not other factors associated with insulin resistance, acutely enhances colorectal epithelial proliferation in vivo. Endocrinology, 147, 1830-7.

Wei EK, Ma J, Pollak MN, et al (2005). A prospective study of C-peptide, insulin-like growth factor-I, insulin-like growth factor binding protein-1, and the risk of colorectal cancer in women. Cancer Epidemiol Biomarkers Prev, 14, 850-5. 